\title{
Erratum to: Biosynthesis of $\beta(1,3) /(1,6)$-glucans of cell wall of the yeast Candida utilis ATCC 9950 strains in the culture media supplemented with deproteinated potato juice water and glycerol
}

Anna Bzducha-Wróbel · Stanisław Błażejak • Magdalena Molenda $\cdot$ Lidia Reczek

Published online: 4 April 2015

(C) Springer-Verlag Berlin Heidelberg 2015

Erratum to: Eur Food Res Technol (2015) 240:1023-1034 DOI 10.1007/s00217-014-2406-6

In the original publication, the description of part figures in figure caption 2 contains some errors. The corrected caption and the Fig. 2 are given on the next page.

The online version of the original article can be found under doi:10.1007/s00217-014-2406-6.

\footnotetext{
A. Bzducha-Wróbel $(\bowtie) \cdot$ S. Błażejak $\cdot$ M. Molenda Department of Biotechnology, Microbiology and Food Evaluation, Faculty of Food Science, Warsaw University of Life Sciences-SGGW, Nowoursynowska Str. 159c, 02-776 Warsaw, Poland

e-mail: anna_bzducha_wrobel@sggw.pl

L. Reczek

Department of Civil Engineering, Faculty of Civil and Environmental Engineering, Warsaw University of Life Sciences-SGGW, Nowoursynowska Str. 159c, 02-776 Warsaw, Poland
} 

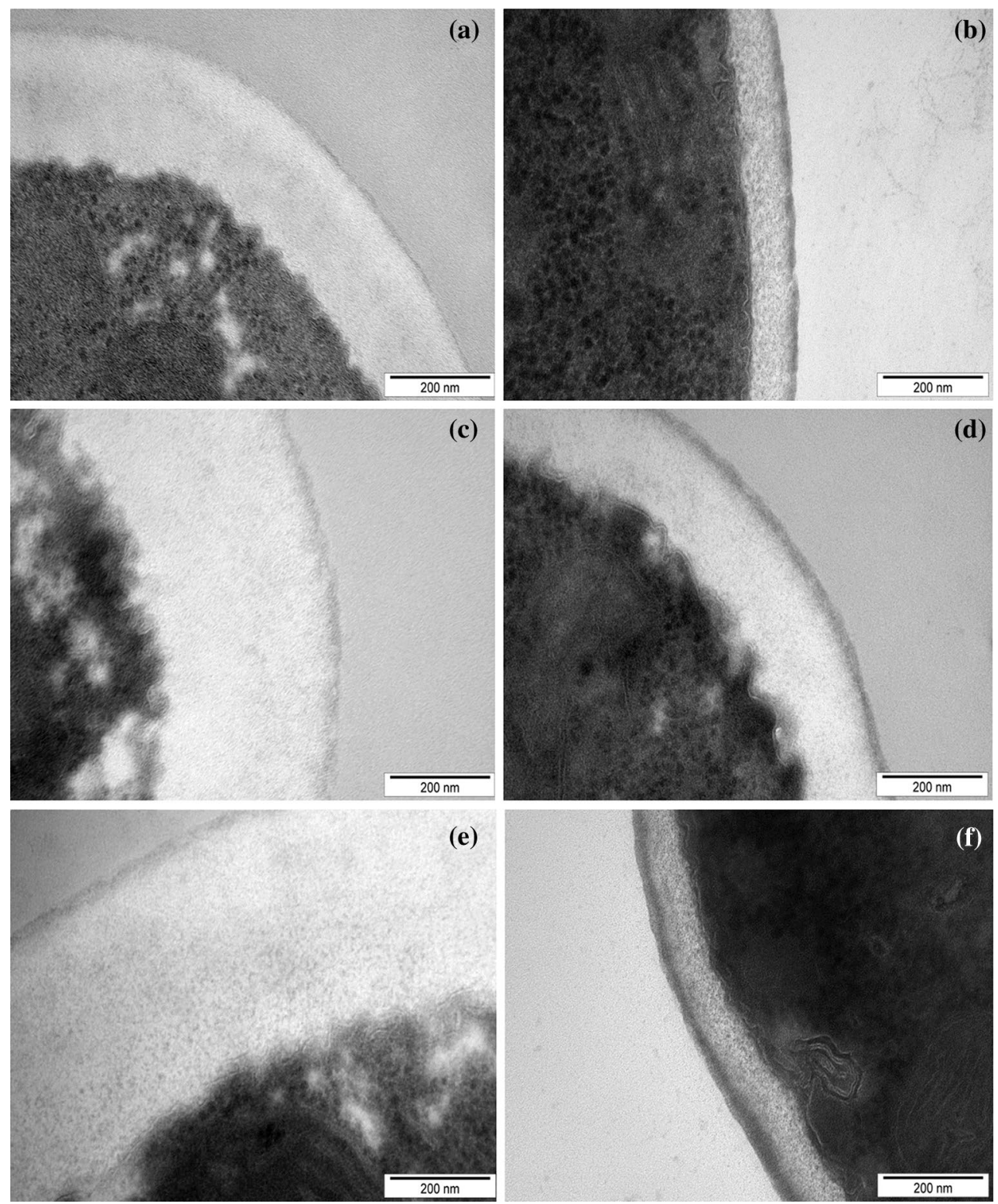

Fig. 2 Exemplary microscopic (TEM) photographs of the yeast $C$. utilis ATCC 9950 strain cell walls from experimental media. a YPD, b pH $4 \_25 \%, \mathbf{c}$ pH 5_5 \%,d pH 5_25\%,e pH 5_10\% and f pH 7_25\% 